\title{
Beste professional \\ in sociaal werk,
}

\begin{abstract}
Met dit bericht willen we allereerst ons respect tonen aan alle professionals die momenteel onder moeilijke omstandigheden hun belangrijke werk blijven doen. Soms met gevaar voor eigen gezondheid en met de verantwoordelijkheid anderen niet te besmetten. Je bent van grote betekenis voor mensen die juist nu soms extra begeleiding, ondersteuning en hulp nodig hebben.

Door Jan Laurier \& Jan Willem Bruins
\end{abstract}

Alle professionals in sociaal werk worden in deze corona-crisis door het ministerie van VWS tot de cruciale beroepen gerekend. Het gaat om professionals bij Veilig Thuis, in wijkteams, jeugdhulp en jeugdzorg, ziekenhuizen, verpleeghuizen, bedrijfsmaatschappelijk werk, reclassering, gehandicaptenzorg, ggz, opvang, jongerenwerk en nog meer vormen van sociaal werk.

Nu de preventieve corona-maatregelen grotendeels tot 1 juni van kracht blijven, zal dat ook van jou extra uithoudingsvermogen vragen en soms tot moeilijke en spannende situaties leiden. Opeens is het noodzakelijk meer digitaal te werken en, waar dat niet kan, te zoeken naar veilige vormen om toch nabij te zijn. Nieuwe problemen die ontstaan als gevolg van de crisis: spanningen of onveiligheid in thuissituaties, financiële problemen, meer eenzaamheid. Het vraagt veel van je om in deze crisis je werk te doen.

De BPSW probeert je daarbij zo goed mogelijk te ondersteunen. Hoe kun je opeens digitaal gaan werken? En wat betekent dat voor je werkrelatie, voor methoden en interventies, voor privacy? Hoe kun je veilig werken als je geen digitale alternatieven voor contact hebt? Hoe ga je om met crisissituaties als je niet bij mensen thuis kan komen? Hoe ondersteun je mensen die in de financiële problemen komen? Voor al dit soort vragen hebben we een speciaal corona-dossier voor je gemaakt dat we steeds up-to-date houden. Je vindt het hier: https://www.bpsw.nl/dossiers/ coronavirus/

Daarnaast gebruiken we social media om kennis en informatie te delen. Volg ons op LinkedIn via BPSW en via de medewerkers Magteld Beun, Gea Kosters, Maroeska Pieters, Jan Willem Bruins.

We werken in deze moeilijke tijd nauw samen met andere beroepsverenigingen, brancheverenigingen en kennisinstituten. En we vertegenwoordigen onze beroepsgroep waar mogelijk en nodig bij de betrokken ministeries waar veel corona-beleid wordt voorbereid.
Wil je iets kwijt aan ons?

Als je vragen hebt, kun je uiteraard via ons spreekuur contact zoeken. Daarnaast horen we graag hoe we ons werk voor jullie nog beter kunnen doen. We krijgen al veel reacties van jullie. Heb je zorgen, ideeën of adviezen, laat het ons weten. Heb je behoefte aan (digitale) vormen van ontmoeting met collega's, zoek contact met ons. Wij kunnen organiseren en faciliteren. Je kunt contact met ons opnemen viainfo@bpsw.nl.

We wensen jullie in deze spannende tijd veel sterkte, voldoende energie en behoud van gezondheid toe.

Namens het bestuur en bureau van de BPSW,

Jan Laurier

Jan Willem Bruins 


\section{BPSWeetjes}

Tweede ambassadeursgroep jeugd in opleiding gestart

De tweede ambassadeursgroep jeugd in opleiding is van start. De ambassadeurs geven stem en gezicht aan de diversiteit van het werk in de jeugdhulp. Gedurende heel 2020 gaan zij aan de slag met thema's als 'stelsel \& financiering', het maken van een pitch, persoonlijk leiderschap en 'leren debatteren'. De ambassadeurs zijn onder meer werkzaam bij AKJ, Veilig Thuis en de Raad, als zzp'er in een orthopedagogische praktijk, als schoolpsycholoog of op een groep in een GI.

Bij- en nascholingsprogramma voor bedrijfsmaatschappelijk werkers na de zomer van start Na de zomer van 2020 start de BPSW school met een modulair aanbod voor bedrijfsmaatschappelijk werkers. Er worden 1 - en 2-daagse trainingen aangeboden rond diverse onderwerpen. Voor 2020 staan (in overleg met de functiegroep BMW) de volgende thema's op de planning: arbeid en rouw, het versterken van je rol als vertrouwenspersoon, arbeid en (een vermoeden van) autisme, stressmanagement/ coaching, profileren en positioneren van het BMW bij een klant of in een organisatie. Meer informatie vind je op bpsw.nl.

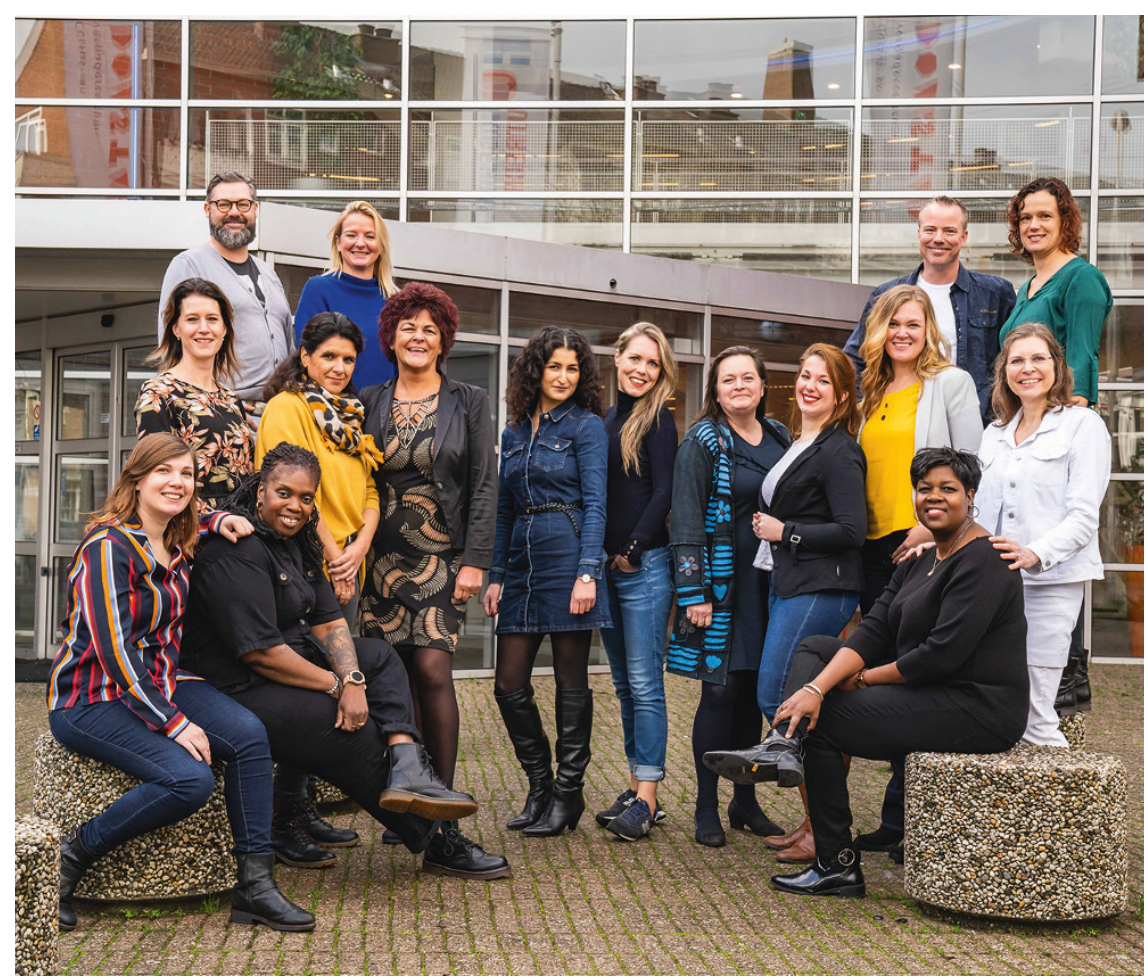

\section{Nieuwe koers BPSW}

In de herfst en winter van 2019 voerden leden, bestuur en bureau in het hele land gesprekken over de nieuwe koers van de BPSW. Vragen die centraal stonden waren onder meer: Welke ontwikkelingen in de samenleving en het werkveld zijn van invloed op het krachtenveld waarbinnen de BPSW opereert? Wat bindt ons als professionals? Wat onderscheidt ons van anderen? De planning van de uitwerking van de nieuwe koers is wat gewijzigd. Op dit moment zijn we bezig om de opbrengst van de gesprekken te verwerken in een koersnotitie. Deze koers is de basis voor het nieuwe strategische beleidsplan van de BPSW voor de periode 2020-2025. Meer weten? Volg het proces op onze website: https://www.bpsw.nl/overbpsw/nieuwe-koers/

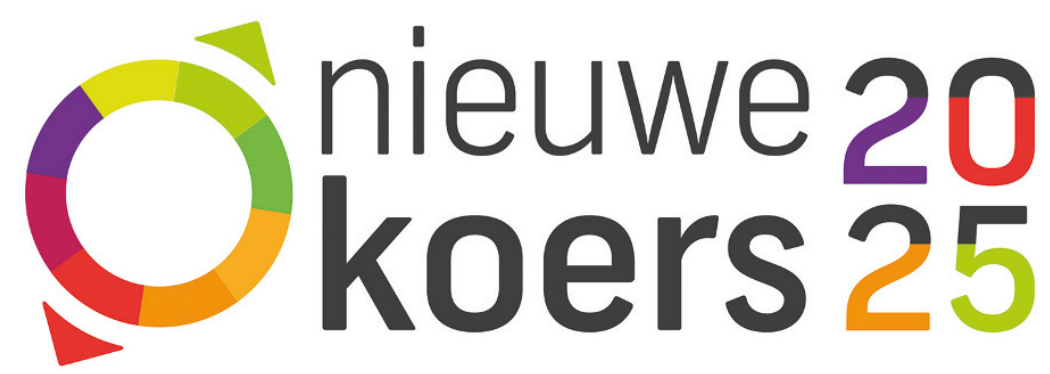




\title{
Richtlijn palliatieve zorg biedt handvatten voor laatste levensfase
}

\author{
Hoe ga je als begeleider in de verstandelijke \\ gehandicaptenzorg om met de laatste \\ levensfase van cliënten? Wat vraagt het van je \\ en wat kan je helpen? De Richtlijn Palliatieve \\ zorg voor mensen met een verstandelijke \\ beperking geeft handvatten. We spraken erover \\ met Erwin Schenzel, coördinator en consulent \\ palliatieve zorg bij Stichting Philadelphia \\ Zorg, en betrokken bij de ontwikkeling van de \\ richtlijn. \\ Door Desiree Weyburg
}

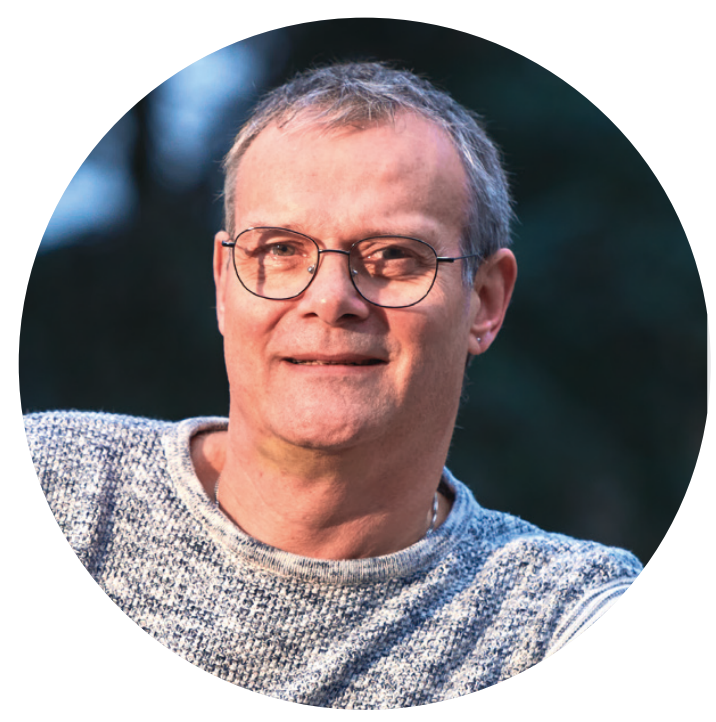

Waarom is het belangrijk om mee te werken aan deze richtlijn? 'Het is belangrijk om als sector gezamenlijk te werken aan de herziening van de richtlijn uit 2010. Ieders expertise is van belang; mooi dus om ook de mijne te mogen delen. De richtlijn gaat over goede zorg in de laatste levensfase van cliënten. Deze fase vraagt andere zorg van begeleiders en dus moeten we er, zeker bij onze cliënten, aandacht voor hebben.'

\section{Hoe draag jij bij aan de richtlijn?}

'Ik werk mee in twee werkgroepen: Markering en Nazorg. Die laatste gaat over zorg na het overlijden. Denk aan de eventuele contactmomenten of herdenkingsdienst met familie en naasten, maar ook aan de zorg voor de zorgenden. Begeleiders hebben vaak een jarenlange band met hun cliënt. Ook zij kunnen rouw ervaren. We vergeten nog weleens na te praten. In de laatste levensfase kun je geconfronteerd worden met dilemma's. Je vond bijvoorbeeld een slaapdienst in die fase spannend, maar durfde dat niet aan te geven bij je team. Of je ervoer heftige emoties omdat je net zelf een dierbare had verloren. Ruimte om hierover te praten is belangrijk voor jezelf én om je werk goed te blijven doen.'

\section{En de tweede werkgroep: Markering?}

'Dat is de fase waarin we ons moeten afvragen:

"Zou het ons verbazen als deze cliënt binnen een jaar overlijdt?” Een complexe vraag om te beantwoorden. Zeker bij cliënten met een meervoudige beperking. Of als er geen sprake is van ernstige ziekte. Je moet signalen opvangen en serieus nemen en goede vragen stellen. Bij het signaleren helpt het als begeleiders met een agogische en met een verpleegkundige achtergrond samenwerken. Uit onzekerheid de vraag niet stellen is geen optie. Juist in die laatste levensfase kun je nog zoveel betekenen als begeleider.'

Zoals?

'Je kunt kijken welke dagbesteding in deze fase nog haalbaar en waardevol is. Oog hebben voor comfortzorg: Hoe maak je het leven voor je cliënt zo aangenaam mogelijk? Heeft hij of zij nog een bucketlist? Kun je nog aansluiten bij het leven van vroeger? Eten en drinken aanbieden waar hij of zij van houdt.'

\section{Dat klinkt mooi, maar kost dat niet heel veel tijd?}

'Dat hoeft niet als je andere taken en patronen in je werk los durft te laten. Er is geen blauwdruk voor de zorg in deze fase. Iedere cliënt is een individueel uniek mens. Als je aansluit bij zijn of haar behoefte op dat moment dan levert dat minder werkstress op en meer ruimte voor betekenisvolle momenten.'

\section{Hoe kan de richtlijn hierbij helpen?}

'Deze biedt handvatten voor op de werkvloer. Maak je die jezelf eigen, dan kun je in de laatste fase van iemands leven verschil maken. Ieder mens leeft, sterft en rouwt op zijn eigen manier. De richtlijn helpt je om cliënten en hun naasten daarbij goed te ondersteunen.'

De herziene Richtlijn palliatieve zorg voor mensen met een verstandelijke beperking is naar verwachting vanaf de zomer 2020 beschikbaar. Houd de website van de BPSW hiervoor in de gaten. 


\section{In the spotlight: de young professional}

\section{'Ik wil me inzetten voor dove en slechthorende cliënten die zichzelf} moeilijk redden'

\section{Ricardo van de Ridder werkt als begeleider op een locatie waar doven en mensen met een verstandelijke beperking zelfstandig wonen. We vroegen hem waarom hij voor dit werk koos en welke ambities hij heeft.}

Door Nienke Post

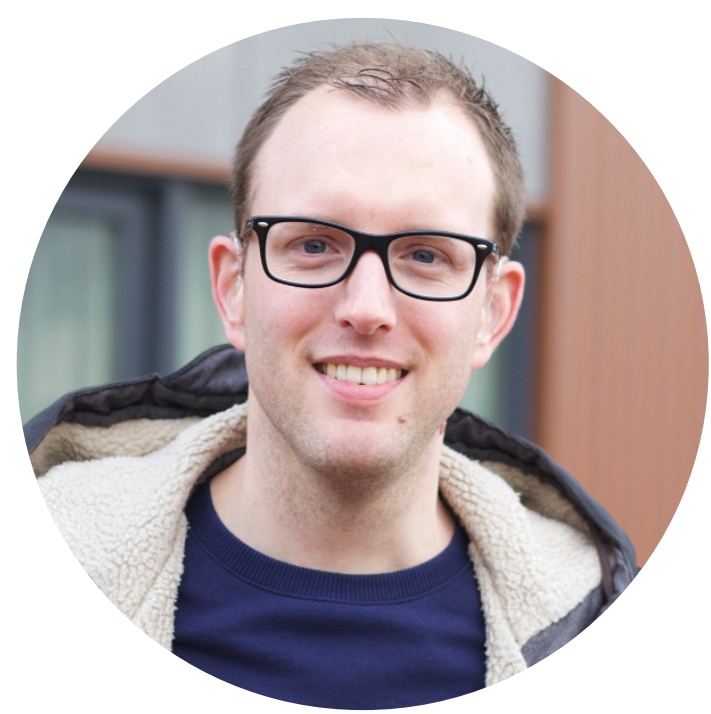

Waarom heb je gekozen voor de studie Maatschappelijk Werk en Dienstverlening?

'Ik vind het belangrijk dat mensen gelijke kansen hebben en dat er respect is voor ieders persoonlijke autonomie en waardigheid. Ik wil dat iemand met een beperking wordt geholpen door het wegnemen van fysieke en sociale drempels, zodat hij of zij kan meedoen in de samenleving. Ook wil ik in mijn werk mensen ondersteunen om hun hulpvragen zelf te kunnen oplossen in hun netwerk.'

\section{Wat is jouw persoonlijke drive als sociaal werker?} 'Ik wil me inzetten voor dove en slechthorende cliënten die het moeilijk vinden om zichzelf te redden. Zelf heb ik met verschillende hulpinstanties te maken gehad omdat ik doof ben. Ik heb zelf belemmeringen ervaren om mee te doen in de maatschappij. Ik wil voor mijn cliënten het dove rolmodel zijn dat zijn draai heeft gevonden in de samenleving.'

Heb je je tijdens je opleiding gespecialiseerd in een bepaald onderwerp?

'Ik heb bewust gekozen voor stages bij instellingen die zich richten op doven en slechthorenden. Naast deze specialisatie heb ik gekozen voor een stage bij een ggz-instelling om GGZ-Agoog te kunnen worden. Ik ben gespecialiseerd in herstelgericht werken en het inzetten van ervaringsdeskundigen bij sociaal werk.'
Wat zou je na je studie nog willen leren?

'Ik wil kennis ontwikkelen over de veranderingen van de sociale zekerheid in Nederland, de verschillende voorzieningen die er zijn zoals de Wmo van de gemeente of de Wet langdurige zorg en van veranderende wetgeving. Door regelmatig scholingen te volgen, blijf ik op de hoogte van ontwikkelingen in mijn vak; en ik lees vaktijdschriften.'

Wat verwacht je van je lidmaatschap van de BPSW? 'Ik verwacht dat we samen laten zien hoe belangrijk sociaal werk is. Vaak hebben cliënten met problemen onze hulp nodig om weer verbinding te maken met de samenleving. Wij zijn als sociaal werkers onmisbaar omdat wij een opvangnet zijn voor cliënten die terugvallen in hun oude patronen. Ik zou daarnaast wel een scholing willen volgen bij de BPSW. Sociaal werk in de digitale samenleving, online hulpverlenen, vind ik een interessant onderwerp.'

Welke uitdagingen zie je voor jezelf als startende professional? 'Hoe kan ik ervaringsdeskundigen inzetten in mijn werk? De taken die ik nu verricht, kunnen voor een deel worden overgenomen door ervaringsdeskundigen. Diegene zou bijvoorbeeld de cliënt kunnen ondersteunen bij praktische zaken. Voor mij als professional zou dit betekenen dat ik meer tijd heb om andere taken te verrichten. Het is een mooie uitdaging om deze samenwerking goed te organiseren!' 